Research Article

\title{
Efficacy of ozonized sunflower oil as treatment of canine generalized demodicosis
}

\author{
Zullyt Zamora Rodriguez ${ }^{1 *}$, Marielys Lemus², Eduardo Fleitas \\ González ${ }^{3}$ and Oscar Ernesto Ledea Lozano ${ }^{4}$ \\ ${ }^{1}$ Veterinary Medicine Doctor, PhD and Assistant Professor, Ozonized Products Groups, National \\ Centre for Scientific Research and Veterinary Medicine Faculty, Agrarian University of Havana, Cuba \\ ${ }^{2}$ Veterinary Medicine and Zootechnics Doctor, Clinic Laboratory of Veterinary Clinic José Luis Callejas, \\ Habana, Cuba \\ ${ }^{3}$ Veterinary Medicine and Zootechnics Doctor, Clinic Veterinary Clinic Almiqui, Habana, Cuba \\ ${ }^{4}$ Chemistry, DsC. Department Analytical Chemistry and Pharmaceutical Formulations, Research of \\ Ozonized Products Units, National Centre for Scientific Research, Havana, Cuba
}

\section{Abstract}

Background: The acaricidal action of Ozonized sunflower oil (OSO) has demonstrated in different clinical cases of different animal species, such as psoroptic rabbits and pig sarcoptic scabies and recently in demodesic goat.

Objectives: This study evaluated the effectiveness of OSO as treatment for generalized demodicosis mange in dogs.

Animals: Twenty dogs of different breeds, between six months and one year of age with generalized demodicosic mange that attended to Veterinary Clinic "José Luis Callejas" Havana, Cuba, during the year 2015, were included in the study.

Methods: The demodicosis diagnostic was based on its clinical history, the mite's presence by deep scraping and clinical signs. All cases had a history of receiving before conventional treatments without solution. OSO treatment was topically applied daily, every 12 hours, after shaving all affected areas. Monitoring of clinical signs, mite counting on scaling, pruritus and capillary regrowth $(7,14,28,56$ and 84 days) were performed.

Results: The results showed a significant reduction of mite counts, clinical signs and pruritus since the $7^{\text {th }}$ day of application. The animals recovered the fur on more than $90 \%$ of the body surface. All the animals $(100 \%)$ recovered from generalized demodesic mange in 84 days of treatment.

Conclusion: The effectiveness and safety of OSO as election treatment of generalized demodicosis mange in dogs was demonstrated.

\section{Introduction}

Demodicosis is a parasitic inflammatory skin disease of dogs caused by an excessive proliferation of Demodex canis [1]. A small number of mites may constitute a normal component of the dog's skin fauna [2], but a proliferation of mites can lead to serious disease. The parasite is not considered contagious except during a few days after birth, when puppies acquire mites through direct skin contact from their mother. Three morphologically different types of Demodex have been

\section{More Information}

*Address for Correspondence:

Zullyt Zamora Rodriguez, Veterinary Medicine Doctor, PhD and Assistant Professor, Ozonized Products Groups, National Centre for Scientific Research and Veterinary Medicine Faculty, Agrarian University of Havana, Cuba,Tel: 53 53056529, Email: zullyt.zamora@cnic.cu

Submitted: February 26, 2021

Approved: March 16, 2021

Published: March 18, 2021

How to cite this article: Rodriguez ZZ, Lemus $M$, González EF, Lozano OEL. Efficacy of ozonized sunflower oil as treatment of canine generalized demodicosis. Insights Vet Sci. 2021; 5: 015-021.

DOI: 10.29328/journal.ivs.1001030

ORCiD: orcid.org/0000-0002-9387-3761

Copyright: (c) 2021 Rodriguez ZZ, et al. This is an open access article distributed under the Creative Commons Attribution License, which permits unrestricted use, distribution, and reproduction in any medium, provided the original work is properly cited

Keywords: Ozonized; Sunflower oil; Demodicosis: Dogs; Demodex canis; Treatment; Mite

\section{Check for updates}

OPEN ACCESS described and named as species by some authors (D. canis, $D$. injai, and D. cornei) $[3,4]$.

Canine generalized demodicosis is frequently seen in the clinical practice [5] and is characterized by five or more affected areas or by lesions covering an entire region of the body, and/or pododemodicosis involving two or more paws [6]. The affected areas are erythematous, with comedones, hair loss, follicular papules to pustules and scales. Lymphadenopathy is commonly associated with the disease 
and secondary bacterial infections are very frequent [3]. The diagnosis is typically based on clinical signs and is confirmed by the presence of mites in deep skin scrapings. Finding more than one mite is strongly suggestive of clinical demodicosis $[3,4]$.

Amitraz, as a rinse or sponge-on, has approved for the treatment of canine generalized demodicosis in many countries for decades. Several amitraz-based protocols was described at various concentrations and frequencies [7]. Protocols based on daily to weekly oral or subcutaneous injections of macrocyclic lactones including ivermectin, doramectin, and moxidectin have been published but represent off-label use with potential for toxicity, especially in dogs mutated for MDR-1 (P-glycoprotein deficiency), especially including colley breeds $[4,7,8]$. Also daily oral milbemycin oxime at a dose of $500 \mathrm{mg} / \mathrm{kg}$ is registered in many countries for the treatment of canine demodicosis [1]. Whatever the choice of the antiparasitic drug, the duration of the treatment of demodicosis usually requires three months or more [9]. Certifect ${ }^{\circledR}$ is a spot-on formulation that combines fipronil, amitraz, and (S)-methoprene. The addition of amitraz to fipronil has shown to significantly potentiate the acaricidal effects of fipronil $[10,11]$. The product has been recently demonstrated to be active against sarcoptic mange [12]. Fluralaner (Bravecto ${ }^{\circledR}$, Merk Animal Health; Madison NJ, USA) is a long acting systemic insecticide and acaricide belonging to the isoxazoline class of parasiticides with selective inhibition of arthropod gamma-aminobutyric acid and L-glutamate gated chloride channels. It is an inhibitor of the arthropod nervous system. An oral single dose of fluralaner proved to be $>99 \%$ effective against fleas and ticks over a period of 12 weeks $[13,14]$. Two studies reported the efficacy of fluralaner in canine generalized demodicosis, both showing that fluralaner can decrease the number of demodex mites by $100 \%$ after 2 months [15-17]. Isoxazolines are safe for dogs with the MDR-1) mutation [18].

Ozonized Sunflower oil (OleoVet) have been well physico chemically characterized [119-22]. In addition, its antibacterial activity was demonstrating on in vitro studies [23-25]. This pharmaceutical product has demonstrated a beneficial effect as treatment of different dermatological parasitic diseases in domestic animal, such as in rabbits psoroptic scab [26], pigs sarcoptic mange [27] and localized demodesic scab in Goat species [28].

Additionally, antiparasitic action of OSO was evidence too. The in vitro antigiardiasic action of OSO was demonstrated [29] and in vivo [30] studies. Recently a clinical trial demonstrated its effectiveness as a treatment of giardiasis in beagle dogs [31].

Based on these findings, the purpose of the present study was to determine the efficacy of topical administration of OSO in dogs with generalized demodicosis.

\section{Materials and methods}

The study was conducted as a nonblinded, controlled open label trial. Pet owners provided written consent and the study was approved by the Animals Care and Use Committee of the National Center for Scientific Research.

\section{Ozonized sunflower oil obtain}

The sunflower oil was placed in a jacketed bubbling reactor at a controlled temperature of $25 \pm 0.1{ }^{\circ} \mathrm{C}$. A mixture of $\mathrm{O}_{3} / \mathrm{O}_{2}$ was continuously bubbled into the solution through a diffuser placed at the bottom of the reactor. The ozone was generated from pure oxygen in an Trailigaz OZAT CFS-7, France, ozone generator and its concentration was determined by measuring the absorbance at $254 \mathrm{~nm}$ in an Anseros ozone analyzer, Germany.

\section{Inclusion criteria}

Participants were client-owned dogs diagnosed with generalized demodicosis between January 2015 and march 2016. Medical records, including previous acaricidal treatments and underlying diseases (for adult-onset cases) were documented. Demographic data recorded, including age between sex months to one year, breed and gender (males and females). Breed distributions were not compared to the general hospital populations to ascertain breed specific risk for disease.

\section{Exclusion criteria}

Puppies less than 6-weeks-old and dogs weighing less than $2 \mathrm{~kg}$, pregnancy animals were excluded from the study.

Following all this inclusion and exclusion criteria, the study was performed with twenty dogs of different breeds (males and females) weighing from 6 to $19 \mathrm{~kg}$ and being at least 1-year old. The owner give the consentient to participate on the study. All had clinical signs of Demodex infestation such as erythema, hair loss, seborrhea, follicular casts, scales, and crust in at least five spots or on an entire body region. All animals included in the study has received traditional treatment for more than two times before, without diseases solution.

\section{Clinical methods}

Generalized demodicosis was defined as more than four small areas $\left(<100 \mathrm{~cm}^{2}\right)$ on the body affecting by demodex, at least one $<100 \mathrm{~cm}^{2}$, or at least one paw. Five deep skin scrapings, from five affecting areas, were taken in each dog exhibiting at least five lesion areas. The surface of each lesion skin scraping was four $\mathrm{cm}^{2}$, using a blade until capillary oozing occurred. The diagnosis of demodicosis was based on finding more than three live adults Demodex canis mites from at least three or more scrapings, or from lesions $>100 \mathrm{~cm}^{2}$ or from a lesional paw [32]. The scrapings were mixed with oil and examined under a stereomicroscope. 
The average of percentage reduction in mite counts was calculated by:

Reduction $\%=\mathrm{GM}$ inclusion - GM post-treatment/GM inclusion X 100

Where GM Inclusion = the geometric Mean (GM) of the Inclusion (pre-treatment) mite counts, and GM post treatment $=$ the geometric mean of the post-treatment mite counts.

Clinical signs and the extent of demodectic lesions on each dog were assessed on the days when scraping were made [33]. At each clinical examination, the clinician determined as Skin Lesion Score (SLS) based upon the principles of the Canine Atopic Dermatitis Extent and severity Index, CADESI [34], but adapted for the lesions of generalized demodicosis. This SLS evaluates lesions including erythema, erosions, comedones/ papules/pustules, scales/crust at least five spots or on an entire body region from zero (normal) to five (severe).

A semi-quantitative assessment of hair regrowth was made. The skin surface of the dogs on which hair regrowth occurred, compared to pretreatment observations, was occurred as 1 if < 50\% hair regrowth, 2 if 50\% - 90\% regrowth occurred, and 3 if $>90 \%$ hair regrowth took place [33].

The owners rated the current pruritus on the day of consultation on a visual score from 0 (no pruritus visible) to 10 (severe pruritus), using a validated pruritus scale $[35,36]$. Furthermore, owners rated the overall condition before and after treatment as improved, deteriorated or unchanged.

The treatment of OSO was as a fine line on the lesions areas applied every 12 hours (at mornings and at night) previously the lesions areas were shaved. The owner of the dogs were the responsible for the treatment. All the dogs were evaluated every two weeks for 12 weeks: four skin scraping were taken from four initially effected areas and the clinical evaluation of CADESI, hair regrowth and pruritus scale were registered every two weeks for 12 weeks. Side effects were recorded during the study period.

In this study, the efficacy of OSO was defined as the absence of demodex canis mites in any life stage at monthly scraping for eight consecutive weeks. These dogs received no other treatment against ectoparasites during the study period.

\section{Statistical methods}

All the dates were analysis by One-way analysis of variance, using for normal distributed variables with Tukey's multiple comparison test. All the statistical analysis were performed by GraphPad Prism Version 5 program. Continuous data are represented as means \pm standard desviation. Statistical significant was set at $p \leq 0.05$.

\section{Results}

The primary assessment variable in the study was the decrease in total number of mites counted in skin scrapings following OSO treatment. The OSO treatment applied by topical way reduced significantly the mean mite number present in skin scrapings at 28, 56 and 84 days of treatment, representing (25.4, 3.9 and 0 mite, respectively) compared to mite counted before treatment (54.3 mites), representing 54, 93 and $100 \%$ of reduction, respectively (Figure 1).

Generally, improvement become evident in all dogs included in the study, within two weeks (14 days) after OSO treatment started, by decreased score lesion skin (SLS) severity of affected areas (Figure 2). OSO reduced significantly $(62.9,86$ and $100 \%$ reduction $)$ the SLS at $+7,+14$ and +56 days, respectively after treatment, compared to before treatment. The SLS was totally reduce at 84 days of treatment. The dog's owner reported no side effects during the treatment.

The presence of pruritus was another clinical signs registered in this study. Surprisingly, the OSO reduced pruritus score significantly in all dogs included in the study, with reduction percent of $51 \%$ and $85 \%$ at 7 and 14 days of treatment, respectively (Figure 3). The pruritus reduction, as a main signs of allergic- inflammatory reaction from the skin parasite with demodex canis, it was in correspondence to the reduction of the SLS at 7 and 14 days of treatment with OSO (Figure 2).

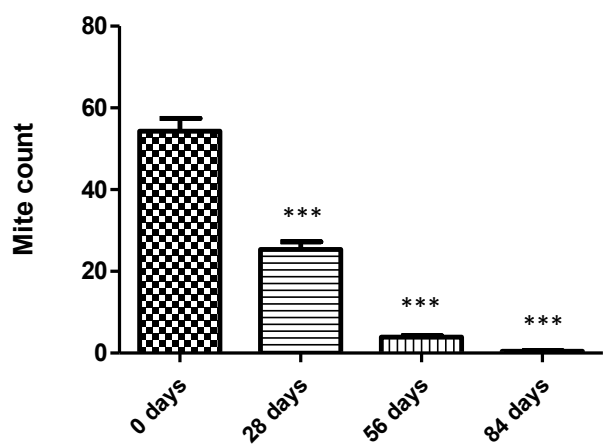

Evolution time

Figure 1: Results of Mite count (Adult demodex canis) in animals treated with OSO at different evolution time. ${ }^{* * *} p<0,001$ significant differences respect to mite count at 0 day. Compare by tukey's multiple comparison test.

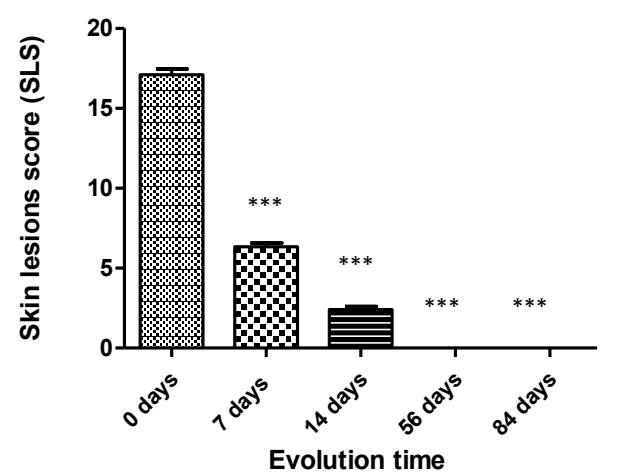

Figure 2: Effect of OSO treatment on the skin lesion score, before ( 0 days) and at different time of evolution $(7,14,56$ and 84 days after treatment). The date express the media and SEM from each evolution time. ${ }^{* * *} p<0,001$ significant differences respect to mite count at 0 day. Compare by tukey's multiple comparison test. 


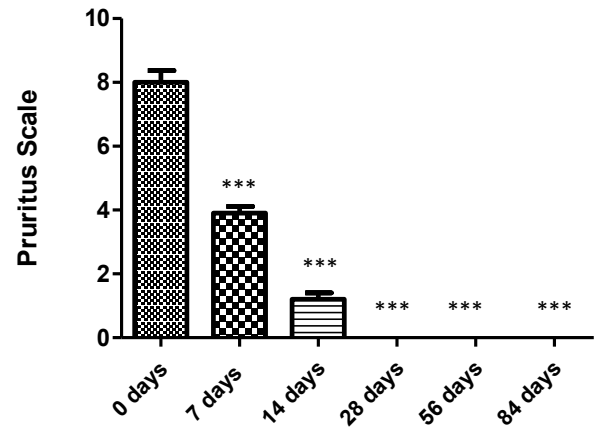

Evolution time

Figure 3: Pruritus scale in animals treated with OSO. The evolution at different times. ${ }^{* * *} p<0.001$ significant differences respect to mite count at 0 day. Compare by Tukey's multiple comparison test.

Hair regrowth compared to the proportion of the body covered by hair prior to treatment is in figure 4 summarized. Up to the $56^{\text {th }}$ days of treatment with OSO, the animals recovered in more than $50 \%$ capillary regrowth, while at the 84 days of treatment achieves it in more than $90 \%$. One of the most important observation, was during this evaluation time of the skin dermatitis, the animals experimented firstly between seven and fourteen days an alopecic sign due to the OSO application. Such alopecia was found in correspondence with the reduction of SLS. Alopecia reversibility was demonstrated after 56 days of OSO treatment, and to 84 days, the hair regrowth was observed until $90 \%$ of affected body surface (Figure 4). These results could be seen with better certainty in the figure $6 \mathrm{CD}$ and $\mathrm{EF}$, one of the animals selected.

The SLS decrease was shown too by a representative pictures from one of the cases include in the study before the treatment (Figure 5A,C). Both pictures show, the mean clinical skin changes characteristic of generalized demodicosis, as granulomatous chronic inflammation, erosions, dryness and lichenification, accompanied by alopecia and an opaque appearance in the hair. OSO treatment applied every 12 hours (mornings/nights) during 56 consecutive days evidenced the improvement of the skin damage of the animals with generalized demodicosis. Those are representing in the figure $5 \mathrm{~B}, \mathrm{D}$, where show in this case no lesions in the skin and the recovery of hair regrowth in more than $90 \%$ of the body surface.

Figure 6 A,B, shows the animal's face area before start the treatment, where erosions, scabs, with edematous and granulomatous appearance, as lesions typical of demodesic dermatitis clearly showed. After 21 days of OSO treatment in figure $6 \mathrm{C}, \mathrm{D}$, are shown (left and right, respectively). The reversion of the skin lesions, previously observed in figures. A and B. However, it would be note that this skin healing aspect areas of the animal was accompanied by an obvious alopecia in the affected areas treated with OSO during the 21. This experimental alopecia observed in the animals was reverted since 56 days of treatment applied, where capillary regrowth in more than $90 \%$ was observed (Figure 6E,F).

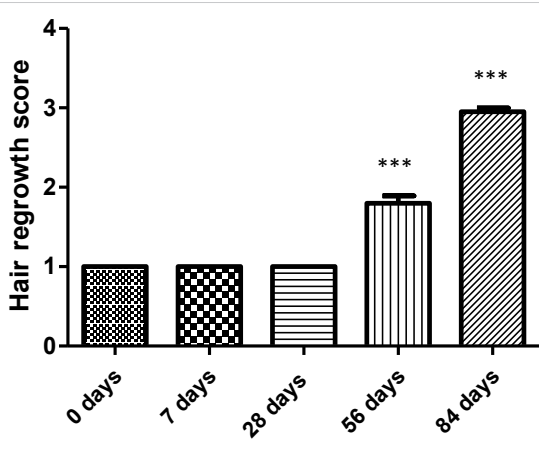

Evolution time

Figure 4: Hair regrowth score in animals treated with OSO. The evolution at different times. ${ }^{* * *} p<0.001$ significant differences respect to mite count at 0 day. Compare by Tukey's multiple comparison test.

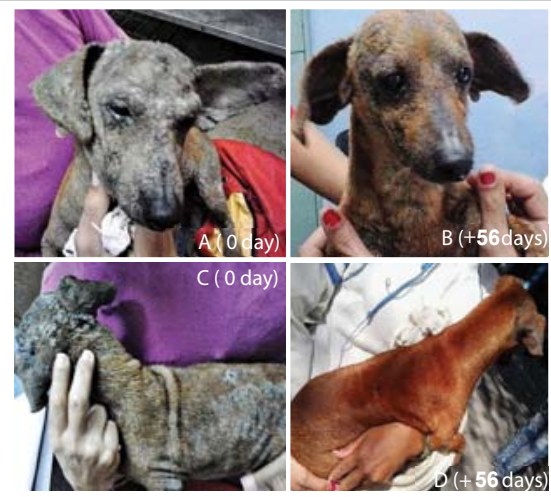

Figure 5: A-D. Pictures represent the clinical evolution of one of the cases with generalized demodicosis included in the study and treated with OSO. Figure A,C. The dog before start the treatment with OSO, Shown the characteristic lesions of generalized demodicosis likes granulomatous chronic inflammation, erosions, dryness and lichenification, accompanied by alopecia and an opaque appearance in the hair. Figure 5B,D, evolution after 56 days of treatment with OSO, it shows no lesions on the skin and regrowth of a new hair almost more than the $90 \%$ of the body surface, with an evident recovery of the shine and health of the hair.

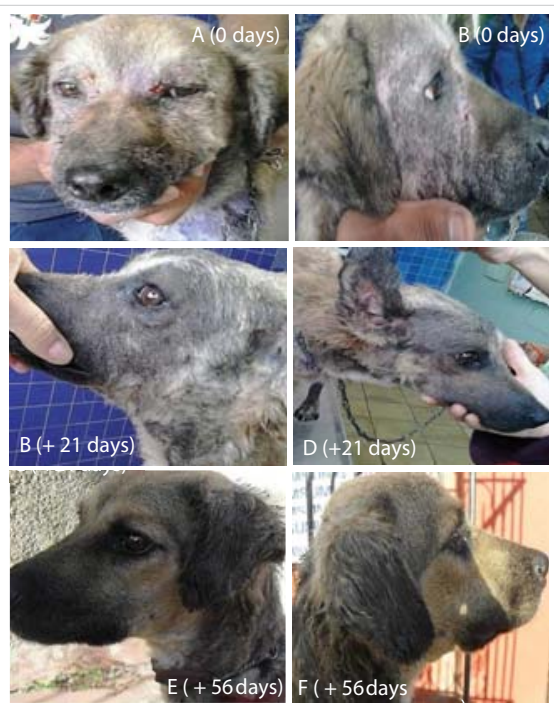

Figure 6: A-F. Pictures represent the clinical evolution of one of the cases with generalized demodicosis included in the study and treated with OSO. Figure A,B shows the clinical aspect from dog's face (frontal and right side, respectively), before the treatment. Both figures show the presence of edematous areas, with erosions, crusts and dryness. Figure C,D show the animal's skin applied 21 days after the OSO, in the area of the face (left and right, respectively). There is no presence of erosive lesions on the skin or edematous areas, but it is worth noting the total loss of hair. Figure E,F show the same case (left and right side areas, respectively), 56 days after the start of treatment. Capillary regrowth of up to $100 \%$ of the surface affected by demodesic dermatitis was observe. 


\section{Discussion}

The present study demonstrates that OSO treatment with for almost for three months, twice a day, resulted in a rapid reduction in mite numbers and a marked improvement in clinical signs, determined as Skin Lesions Score (SLS), in all dogs with generalized demodicosis.

The acaricide OSO action by significant reduction of mites count on parasitize site infection sampled was demonstrated. The decrease of mites account achieved by OSO treatment was in correspondence to the SLS reduction (62\%) after 7 days application and the $100 \%$ of reduction at 56 days. OSOacaricidal action was demonstrated as the main pharmacological effect in different studies both in vitro and in vivo, as in the case of rabbit psoroptic [27] and pig sarcoptic mange [26]. Recently, the effectiveness of OSO was demonstrated as a treatment for localized demodesic mange in goats [37].

Pruritus represent a characteristic clinical sign of the hypersensitivity allergic reaction, induced by the presence of the mite. The pruritus was significantly reduced (51\%), after 7 days of OSO application. These results constitute the first evidence on the effectiveness and safety of AGO treatment in generalized canine demodicosis.

Taking these results into account, the acaricidal action of the OSO was considered the first line of pharmacological action. Additionally, the anti-inflammatory activity of OSO is evidenced in our study by reducing SLS (edema, erythema) and pruritus, corresponding to previously reported experimental results where OSO reduced the edema formation and inflammatory infiltrated cells [38]. The results of experimental studies designed for this purpose [39], as well as a clinical study in horses [40], canines [41]. Associated with the stimulation of endogenous antioxidant enzymes in skin damaged by UV radiation [21] and experimental studies (suggesting the great potential of OSO as a treatment of choice for generalized demodesic mange in dogs.

Oxidative stress (OS) has been implicated in various mite's infestations including canine demodicosis [42,43]. Numerous cytokines and growth factors have been described to generate ROS to transmit information upon binding to their receptors [44]. Therefore, shifting of oxidant/antioxidant balance in demodicosis dogs toward oxidative status could be involved in the progression of canine demodicosis [45]. Considering, another beneficial pharmacological action of OSO, as stimulator of some antioxidant enzymes activity (SOD and GPx). Action that was in different experimental models demonstrated, like orthokeratosis and UV damage skin in rats $[21,46]$. Recently, was demonstrated that SOD activity, as antioxidant enzyme increase in mice skin damage was associated to ozonized oils (00s) healing action [47]. Thus, it suggests, OSO could be able reverts oxidative stress, involved in skin demodicosis infection too.
Actually, the healing mechanism demonstrated for Ozonized oils (OOS), were based on that peroxides presents into the 00s, activated NF kB expression [48], increase the initial inflammatory response [39], thought out the fibroblast infiltration and collagen synthesis, without phases of the process alterations [39]. Therefore, this healing mechanism was accompanied by the increment of growth tissue factors expressions, such as platelet-derived growth factor (PDGF), vascular endothelial growth factor (VEGF) and transforming growth factor- $\beta$ (TGF- $\beta$ ) [49]. However, knowing that this latter factor (TGF- $\beta$ ), is linked to the immunosuppression experienced in demodicosis [50], it is suggested that this factor, according to the favorable results achieved, was not directly linked in. The mechanism of the healing process with the treatment of OSO in cases of generalized demodicosis in canines, and if the rest of the growth factors (PDGF), vascular endothelial growth factor (VEGF).

The capillary regrowth is an important aspect to consider, due to the applied treatment, for the resolution of infestation by demodex canis and lesions caused by demodesic dermatitis. However, during this recovery process of animal's skin, it must emphasize that there was induced alopecia experience, due to application-evaluated product. Such alopecia, took place from 28 days of application product (Figure 6, C,D). The alopecia reversibility seen at 56 days of OSO treatment. In an experimental study demonstrated, that topical application of ozonized olive oil (AOO) in mice produces apoptosis of the matrix of hair follicle cells at 6 days of application, reversing this effect at 35 days of evolution [51].

In general, the effectiveness and safety of OSO applied every 12 hours during 84 days as treatment of generalized demodicosis in canines was demonstrated. Suggesting that firstly, OSO eliminated mites that are parasitizing both hair follicles and sebaceous glands. Together to its proinflammatory/anti-inflammatory action, OSO reverses the immunosuppression process induced by the mites itself, activating the initial inflammatory response (neutrophil and fibroblasts infiltration), important for degrading the detritus produced by the mite. Then, detritus degraded lead to granulomas formation and increase growth factors expression, favoring the healing process. On the other hand, OSO increases the endogenous antioxidant enzymatic activity in the damaged skin, thus reversing the oxidative damage generated by the parasitosis itself and in this way favors the resolution of the generalized demodicosis in canines.

The results indicated as conclusion, that ozonized sunflower oil could be used as choice therapy for generalized demodicosis treatment for dogs.

\section{Acknowledgment}

The authors would like to thanks all the workers and the head of the Clinic of Affective Animals "Jose Luis Callejas", 
Veterinary Medicine Institute, belong from Agriculture Minister (MINAG), Havana, Cuba, how offers us places and the lab for performance this study. Special thanks to the owners and the dogs that participated in the study.

\section{References}

1. Mueller RS, Bensignor E, Ferrer L, Holm B, Lemarie S, et al. Treatment of demodicosis in dogs, 2011 clinical practice guidelines, Vet Dermatol. 2012; 23: 86-e96.

PubMed: https://pubmed.ncbi.nlm.nih.gov/22329600/

2. Ravera I, Altet L, Francino O, Sánchez A, Roldán W, et al. Smal Demodex populations colonize most parts of the skin of healthy dogs. Vet Dermatol. 2013; 24: 168-172.

PubMed: https://pubmed.ncbi.nlm.nih.gov/23331694/

3. Guaguère $E$, Beugnet $F$. Parasitic skin conditions, in A practical Guide to Canine Dermatology, Guaguère $E$, Prélaud $P$, Craig $M$, Eds. Kalianxis: Paris. 2008, 179-226.

4. Mueller R. An update on the therapy of canine demodicosis. Compend Contin Educ Vet. 2012; E1-E4.

PubMed: https://pubmed.ncbi.nlm.nih.gov/22488596/

5. Plant. J, Lund, E, Yang, M. A case control study of the risk factors for juvenile-onset generalized demodecosis in the USA. Vet Dermatol. 2011; 22: 95-99.

PubMed: https://pubmed.ncbi.nlm.nih.gov/20707860/

6. Fourie LJ, Kok DJ, du Plessis A, Rugg D. Efficacy of a novel formulation of metaflumizone plus amitraz for the treatment of demodectic mange in dogs. Vet Parasitol. 2007; 150: 268-274.

PubMed: https://pubmed.ncbi.nlm.nih.gov/17923331/

7. Paterson $T$, Halliwell R, Fields $P$, Louw ML, Louw JP, et al. Treatment of canine-generalized demodecosis: a blind, randomized clinical trial comparing the efficacy of Advocate (Bayer Animal Health) with ivermectin. Vet Dermatol. 2009; 20: 447-455.

PubMed: https://pubmed.ncbi.nlm.nih.gov/20178483/

8. Hutt JHC, Prior IC, Shipstone MA. Treatment of canine generalized demodicosis using weekly injections of doramectin: 232 cases in the USA (2002-2012). Vet Dermatol. 2015; 26: 345-e373.

PubMed: https://pubmed.ncbi.nlm.nih.gov/26190685/

9. Mueller R, Meyer D, Bensignor E, Sauter-Louis C. Treatment of canine generalized demodicosis with a "spot-on" formulation containing $10 \%$ moxidectine and $2.5 \%$ imidacloprid (Advocate, Bayer Healthcare). Vet Dermatol. 2009; 20: 441-446.

PubMed: https://pubmed.ncbi.nlm.nih.gov/20178482/

10. Pfister K. Fipronil, amitraz and (S)-methoprene-a novel ectoparasiticide combination for dogs. Vet Parasitol. 2011; 179: 293-356.

PubMed: https://pubmed.ncbi.nlm.nih.gov/21777729/

11. Prullage JB, Cawthorne WG, Le Hir de Fallois LP, et al. Synergy between fipronil and amitraz in a Rhipicephalus sanguineus tick residual contact test. Exp Appl Acarol. 2011; 54: 173-176.

PubMed: https://pubmed.ncbi.nlm.nih.gov/21243407/

12. Gaxiola S, Gaxiola J, Perez A, et al. Effectiveness of two topical treatments with a combination fipronil/amitraz/(S)-methoprene against natural infestations of mites (Sarcoptes scabiei var. canis) on dogs. Int J Appl Res Vet Med. 2013; 11: 10-15.

13. Gassel M, Wolf $C$, Noack $S$, Williams $H$, llg $T$, et al. The novel isoxazoline ectoparasiticide fluralaner: selective inhibition of arthropod gamma-aminobutyric acid and L-glutamate gated chloride channels and insecticide/acaricidal activity. Insect Biochem Mol Biol. 2014; 45: 111-124.

PubMed: https://pubmed.ncbi.nlm.nih.gov/24365472/

14. Rohdich N, Roepke RK, Zschiesche EA. Randomized, blinded, controlled and multi-centered field study comparing the efficacy and safety of Bravecto ${ }^{\mathrm{TM}}$ (fluralaner) against Frontline ${ }^{\mathrm{TM}}$ (fipronil) in flea- and tick-infested dogs. Parasit Vectors. 2014; 83: 1-5

PubMed: https://pubmed.ncbi.nlm.nih.gov/24593931/

15. Fourie J, Liebenberg J, Horak IG, Taenzler J, Heckeroth AR, et al. Efficacy of oral administration fluralaner (Bravecto ${ }^{\circledR}$ ) or topically applied imidacloprid/moxidectin (Advocate ${ }^{\circledR}$ ) against generalized demodicosis in dogs. Parasit Vectors. 2015; 187: 1-7.

PubMed: https://pubmed.ncbi.nlm.nih.gov/25881320/

16. Karas-tecza J, Dawidowicz J. Efficacy of fluralaner for the treatment of canine demodicosis. Vet Dermatol. 2015; 307: 1-5.

17. Duangkaew L, Larsuprom L, Anukkul P, Lekcharoensuk C, Chen C. A field trial in Thailand of the efficacy of oral fluralaner for the treatment of dogs with generalized demodicosis. Vet Dermatol. 2018; 29: 208-e74. PubMed: https://pubmed.ncbi.nlm.nih.gov/29424108/

18. Walther F, Paul A, Allan M, Roepke RKA, Nuernberger MC. Safety of fluralaner a novel systemic antiparasitic drug, in MDR (-/-) Collies after oral administration. Parasit Vectors. 2014; 7: 86.

PubMed: https://pubmed.ncbi.nlm.nih.gov/24602342/

19. Ledea-Lozano O, Martínez E, Garcés R. Aplicación de métodos cromatográficos en la caracterización del aceite de girasol ozonizado, Revista CENIC Ciencias Químicas. 2005; 36.

20. Ledea-Lozano O. Estudio de la Composición Química del Aceite de Girasol Ozonizado OLEOZON . Revista CENIC Ciencias Químicas. 2004; 35: 33-34.

21. Sánchez Y, Díaz MF, Hernández GD. Antioxidant effects of an ozonized theobroma oil formulation on damaged-inflammatory rat skin. Grasas y Aceites. 2011; 62: 105-110.

22. Díaz M, Gavín J, Ledea-Lozano O. Spectroscopic Characterization of Ozonated Sunflower Oil. Ozone Sci Eng. 2005; 27: 247-253.

23. Ledea LO, Curtiellas V, Moleiro J. Evidencias del Mecanismo Oxidante en la Actividad Antibacteriana del Aceite de Girasol Ozonizado. Revista CENIC Ciencias Químicas. 2010; 41.

24. Curtiellas V, Gómez M, Ledea LO. Actividad Antimicrobiana del OLEOZON ${ }^{\circledR}$ sobre Staphylococcus Aureus y Pseudomonas Aeruginosa. Revista CENIC Ciencias Biológicas. 2005; 36.

25. Curtiellas V, Ledea-Lozano O, Rodríguez S. Efectos del OLEOZON sobre la viabilidad, la permeabilidad celular y la ultraestructura de Staphylococcus Aureus. Revista CENIC Ciencias Biológicas. 2008; 39: $128-131$.

26. Camps RAM, Arias del Toro A. Aplicación tópica del Oleozon como tratamientos alternativos contra la sarna sarcóptica en precebas porcina. Vet Arg. 2013; 308: 1-6

27. Camps RAM, Janine PD, Rosales A. Aplicación tópica del Oleozon en la sarna psoróptica del conejo. Vet Arg. 2012; 293: 1-7.

28. Camps RAM, Milanes VI, De Lourdes O. Aplicación tópica del Oleozón en caso clínico de lesiones del pabellón de la oreja en un perro. Vet Arg. 2016; 333: 1-8.

29. Hernández F, Hernández D, Zamora Z, Díaz M, Ancheta O, et al. Giardia duodenalis: effects of an ozonized sunflower oil product (Oleozon) on in vitro trophozoites. Exp Parasitol. 2009; 121: 208-212. PubMed: https://pubmed.ncbi.nlm.nih.gov/19010325/

30. Zamora Z, Torrez D, Bouza M. Oleozon oral, tratamiento efectivo en la giardiasis experimental, Revista CENIC Ciencias Biológicas. 2006; 37: 45-48.

31. Zamora Z, Sosa I, Gómez D. Efectividad y eficacia del aceite de girasol ozonizado (AGO) de uso oral como tratamiento de la giardiasis en perros Beagles. REDVET. 2016; 17: 1-13.

32. Huang HP, Lien YH. Treatment of canine generalized demodicosis associated with hyperadrenocorticism with spot-on moxidectin and imidacloprid. Acta Vet Scand. 2013; 55: 40.

PubMed: https://pubmed.ncbi.nlm.nih.gov/23663380/ 
33. Fourie J, Dumont $P$, Halos L, Beugnet F, Pollmeier M, et al. Efficacy of a topical application of Certifect (fipronil $6.26 \% \mathrm{w} / \mathrm{v}$, amitraz $7.48 \%$ $\mathrm{w} / \mathrm{v},(\mathrm{S})$-methoprene $5.63 \% \mathrm{w} / \mathrm{v}$ ) for the treatment of canine generalized demodicosis. Parasite. 2013; 20: 46

PubMed: https://www.ncbi.nlm.nih.gov/pmc/articles/PMC3834659/

34. Olivry T, Marsella R, Iwasaki T. Mueller R, International Task Force On Canine Atopic Dermatitis. Validation of CADESI-03, a severity scale for clinical trials enrolling dogs with atopic dermatitis. Vet Dermatol. 2007; 18: 78-86.

PubMed: https://pubmed.ncbi.nlm.nih.gov/17355421/

35. Hill PB, Lau P, Rybnicek J. Development of an owner-assessed scale to measure the severity of pruritus in dogs. Vet Dermatol. 2007; 18 : 301-308.

PubMed: https://pubmed.ncbi.nlm.nih.gov/17845617/

36. Rybnicek J, Lau-Gillard PJ, Harvey R, Hill PB. Further validation of a pruritus severity scale for use in dogs. Vet Dermatol. 2009; 20: 115-122. PubMed: https://pubmed.ncbi.nlm.nih.gov/19171021/

37. Camps RAM, Jiloi A, Milanes VI. Aplicación tópica del Oleozón como alternativa de tratamiento en la sarna localizada en caprinos. Vet Arg. $2016 ; 344$

38. Zamora Z, González Y, Ledón N. Effect of ozonized sunflower oil on Myeloperoxidase activity in the model of ear oedema in mouse REDVET. Revista Electrónica de Veterinaria. 2006; VII.

39. Sánchez AA, Díaz PR, Rodríguez GG. Acción del aceite ozonizado sobre la cicatrización de heridas de piel en animales de experimentación, Revista CENIC, Ciencias Biológicas. 1998; 29: 181-183.

40. Camps AMR, Claro GNJ, Cuesta GA. Aplicación tópica del Oleozón como alternativa de tratamiento en lesiones causadas por fricción en caballos de tiro, considerando algunos indicadores hematológicos, REDVET, Revista Electrónica de Veterinaria. 2006; 7.

41. Camps RAM, Milanes VI, De Lourdes O. et al. Aplicación tópica del Oleozón en caso clínico de lesiones del pabellón de la oreja en un perro. Vet Arg. 2016; 333.
42. Singh SK, Dimri U, Sharma MC, Swarup D, Sharma B. Determination of oxidative status and apoptosis in peripheral blood of dogs with sarcoptic mange. Vet Parasitol. 2011b; 178: 330-338. PubMed: https://pubmed.ncbi.nlm.nih.gov/21324594/

43. Singh SK, Dimri U, Sharma MC. Swarup D, Sharma B, et al. The role of apoptosis in immunosuppression of dogs with demodicosis. Vet Immunol Immunopathol. 2011a; 144: 487-492.

PubMed: https://pubmed.ncbi.nlm.nih.gov/21890219/

44. Thannickal VJ, Fanburg BL. Reactive oxygen species in cell signaling Am J Physiol. Lung Cell Mol Physiol. 2000; 279: L1005-L1028. PubMed: https://pubmed.ncbi.nlm.nih.gov/11076791/

45. Shanker K, Singha B, Umesh D. The immuno-pathological conversions of canine demodicosis. Vet Parasitol. 2014; 203: 1-5. PubMed: https://pubmed.ncbi.nlm.nih.gov/24680602/

46. Martínez G, Merino N, Sam S. Efecto histológico y bioquímica de OLEOZON $®$ en el modelo de la cola del ratón. Revista CENIC. Ciencias Biológicas. 1997; 28: 31-34.

47. Pai SA, Gagangras SA, Kulkarni et al. Potential of Ozonated Sesame Oil to Augment Wound Healing in Rats. Indian J Pharm Sci. 2014; 76: 87-92. PubMed: https://pubmed.ncbi.nlm.nih.gov/24799744/

48. Valacchi G, Lim Y, Belmonte G, Miracco C, Zanardi I, et al. Ozonated sesame oil enhances cutaneous wound healing in SKH1 mice. Wound Repair Regen. 2011; 19: 107-115. PubMed: https://pubmed.ncbi.nlm.nih.gov/21134039/

49. Kim HS, Noh SU, Han YW, Kim KM, Kang H, et al. Therapeutic effects of topical application of ozone on acute cutaneous wound healing. $J$ Korean Med Sci. 2009; 24: 368-374.

PubMed: https://pubmed.ncbi.nlm.nih.gov/19543419/

50. Yarim GF, Yagci BB, Ciftci G. Increased circulating concentrations of PDGF-BB and TGF- 1 in canine generalised demodicosis. Revue Med Vet. 2013; 164: 13-17.

51. Hiromi K, Masanori S, Humitoshi S. Proinflammatory Event of Ozonized Olive Oil in Mice, Ozone: Science \& Engineering. 2009; 31: 238-246. 